\title{
A single point mutation on the cucumber mosaic virus surface induces an unexpected and strong interaction with the F1 complex of the ATP synthase in Nicotiana clevelandii plants
}

\author{
Ákos Gellért ${ }^{\mathrm{a}, *}$, Tímea Pósa ${ }^{\mathrm{b}}$, Attila Fábián ${ }^{\mathrm{c}}$, László Szabód $^{\mathrm{d}}$, Károly Bóka ${ }^{\mathrm{e}}$, Barbara Forróa ${ }^{\mathrm{a}}$, \\ Katalin Salánki ${ }^{\mathrm{f}}$, László Drahos ${ }^{\mathrm{g}}$, Eszter Tóth ${ }^{\mathrm{g}}$, Angéla Juhász ${ }^{\mathrm{c}}$, Ervin Balázs ${ }^{\mathrm{c}}$ \\ ${ }^{a}$ Institute for Veterinary Medical Research, Centre for Agricultural Research, Hungarian Academy of Sciences, Budapest, Hungary \\ b Plant Protection Institute, Georgikon Faculty, Pannon University, Keszthely, Hungary \\ ${ }^{\mathrm{c}}$ Agricultural Institute, Centre for Agricultural Research, Hungarian Academy of Sciences, Martonvásár, Hungary \\ d Institute of Materials and Environmental Chemistry, Research Centre for Natural Sciences, Hungarian Academy of Sciences, Budapest, Hungary \\ e Department of Plant Anatomy, Eötvös Loránd University, Budapest, Hungary \\ f Plant Protection Institute, Centre for Agricultural Research, Hungarian Academy of Sciences, Budapest, Hungary \\ ${ }^{\mathrm{g}} \mathrm{MS}$ Proteomics Research Group, Research Centre for Natural Sciences, Hungarian Academy of Sciences, Budapest, Hungary
}

\section{A R T I C L E I N F O}

\section{Keywords:}

Cucumber mosaic virus

ATP synthase

Host-virus interaction

Capsid protein

Nicotiana clevelandi

\begin{abstract}
A B S T R A C T
A previous study showed that a single amino acid difference in the cucumber mosaic virus (CMV) capsid protein (CP) elicits unusual symptoms. The wild-type strain (CMV-R) induces green mosaic symptoms and malformation while the mutant strain (CMV-R3E79R) causes chlorotic lesions on inoculated leaves and strong stunting with necrosis on systemic leaves. Virion preparations of CMV-R and CMV-R3E79R were partially purified from Nicotiana clevelandii A. Gray and analysed by two-dimensional gel electrophoresis. Their separated protein patterns showed remarkable differences at the $50-75 \mathrm{kDa}$ range, both in numbers and intensity of spots, with more protein spots for the mutant CMV. Mass spectrometry analysis demonstrated that the virion preparations contained host proteins identified as ATP synthase alpha and beta subunits as well as small and large Rubisco subunits, respectively. Virus overlay protein binding assay (VOPBA), immunogold electron microscopy and modified ELISA experiments were used to prove the direct interaction between the virus particle and the $N$. clevelandii ATP synthase F1 motor complex. Protein-protein docking study revealed that the electrostatic change in the mutant CMV can introduce stronger interactions with ATP synthase F1 complex. Based on our findings we suggest that the mutation present in the CP can have a direct effect on the long-distance movement and systemic symptoms. In molecular view the mutant CMV virion can lethally block the rotation of the ATP synthase F1 motor complex which may lead to cell apoptosis, and finally to plant death.
\end{abstract}

\section{Introduction}

Cucumber mosaic virus (CMV) belongs to the genus Cucumovirus and family Bromoviridae, infects more than 1000 plant species and causes serious economic losses. Several CMV strains have been described and divided into two subgroups based on serological relationships and nucleotide sequences (CMV I and CMV II subgroup) (Palukaitis et al., 1992).

Virus CPs have various fundamental roles in the virus life cycle. They protect the viral genome from degradation and are involved in almost every steps of the virus life cycle, including virion assembly; vector transmission; regulation of host defence responses; cell-to-cell and systemic movement of the virus and symptom formation (Palukaitis and García-Arenal, 2003). The indispensability of the CP of CMV in local movement was elaborated in detail by Boccard and Baulcombe (1993), and its role was also reported in systemic infection (Kobori et al., 2002; Ryu et al., 1998). Some loop regions of the CP are responsible for aphid transmission (Liu et al., 2002). CMV CP is involved in the encapsidation by interaction of the basic domain near the $\mathrm{N}$ terminus of CP with the viral RNA (Harrison, 1984). CMV passes through the plant as a virion within the phloem (Taliansky and GarcíaArenal, 1995). These biological functions were demonstrated by using CMV chimeras, recombinants and reassortants, but more importantly with mutant forms of the $\mathrm{CP}$. Mutations in the $\mathrm{CP}$ often affect the

\footnotetext{
* Corresponding author.

E-mail address: gellert.akos@agrar.mta.hu (Á. Gellért).
} 
evolving symptoms. For instance amino acid (aa) position 129 has been identified as a key factor in symptom formation (Mochizuki and Ohki, 2005). Nineteen different amino acids were introduced into this position and they have induced six different types of symptoms on the leaves of infected tobacco species, white mosaic, pale green mosaic, veinal chlorosis, veinal necrosis, systemic necrosis and necrotic local lesions, respectively (Mochizuki and Ohki, 2011). In a different study, one amino acid change in the CMV CP at position 129 has induced chlorosis in tobacco plants (Shintaku et al., 1992).

Virus proteins make several contacts with proteins and other moieties of the host plant during infection. Therefore describing proteinprotein interactions in respect of host-virus relationships have utmost importance e.g.: tobacco mosaic virus and Nicotiana benthamiana system where inhibition of the oxygen-evolving complex of photosystem II enhances the levels of virus accumulation. (Abbink et al., 2002); Protein-protein interaction was also detected in planta and in vitro during viral infection of potato virus X (PVX) in Nicotiana, the NbPCIP1 protein interacting with PVX coat protein plays a role as susceptible factor (Park et al., 2009). Currently, it was demonstrated that CMV capsid protein induces the evolving of chlorotic symptoms through interacting with the chloroplast ferredoxin I protein (Qiu et al., 2018).

In a previous work Salánki and co-workers had created five $\mathrm{CP}$ mutants in order to study the long-distance movement of CMV in cucumber (Salánki et al., 2011). One of these CMV CP mutants, CMVR3E79R, bears a point mutation on the surface of the CP and causes an unusual symptom phenotype (Salánki et al., 2011). The mutant CMV (CMV-R3E79R) induces chlorotic local lesions on the infected leaves and severe malformation combined with stunting, necrosis and eventual death of Nicotiana clevelandii A. Gray plants. In contrast to the mutant virus, the wild-type CMV (CMV-R) causes mild systemic mosaic symptoms. The E/79/R mutation caused significant electrostatic potential changes on the surface of the virion, which we concluded to be responsible for the much stronger symptoms. The aim of our study was to identify $N$. clevelandii host proteins that interact with CMV and to describe the molecular background of the aforementioned unusual symptoms caused by the mutant CMV.

\section{Materials and methods}

\subsection{Virus infection and purification}

Nicotiana clevelandii A. Gray plants were grown in a growth chamber under controlled environmental conditions on a cycle of $14 \mathrm{~h}$ light at $23^{\circ} \mathrm{C}$ and $10 \mathrm{~h}$ dark at $18^{\circ} \mathrm{C}$. $N$. clevelandii plants were inoculated at the 6-8 leaf stage with extracts of infected plants (CMV-R or CMV-R3E79R) homogenized in $20 \mathrm{mM}$ phosphate buffer $\mathrm{pH}$ 8.0. Symptomatic tobacco leaves were harvested and mixed then virion was purified in three technical replicates. CMV purification was performed using the method of Lot and co-workers (Lot et al., 1972), except that chloroform extraction was omitted. Briefly, the fresh leaves were homogenized with two volumes of $0.5 \mathrm{M}$ sodium-citrate buffer $\mathrm{pH} 6.5$ containing $0.5 \mathrm{mM}$ EDTA and $0.1 \%$ thioglycolic acid followed by centrifugation at $6000 \mathrm{~g}$ for $10 \mathrm{~min}$ at $4{ }^{\circ} \mathrm{C}$. Supernatants were pooled and the virions were collected by ultracentrifugation at $78,000 \mathrm{~g}$ for $150 \mathrm{~min}$ at $4^{\circ} \mathrm{C}$. Pellets were resuspended in sodium-citrate buffer and the ultracentrifugation was repeated. Final pellets were each resuspended in $300 \mu \mathrm{L}$ Rabilloud buffer (Rabilloud et al., 1997) containing $5 \mathrm{M}$ urea, $2 \mathrm{M}$ thiourea, $2 \%$ CHAPS, $2 \%$ SB 3-10, 1\% pH 3-10 carrier ampholyte and $50 \mathrm{mM} \mathrm{1,4-}$ dithiothreitol (DTT).

\subsection{Two-dimensional gel electrophoresis (2D GE)}

2D-GE was performed by isoelectric focusing (IEF) in the first dimension with a $\mathrm{pH}$ range of 3-10, followed by SDS polyacrylamide gel electrophoresis (SDS PAGE) in the second dimension. SDS PAGE was carried out on $12 \%$ acrylamide gels. At first, protein samples containing $500 \mu \mathrm{g}$ of protein were re-solubilized in Rabilloud-buffer and uploaded using in-gel rehydration. IEF was performed with step-wise voltageincrease procedure with a total of about $30-35 \mathrm{kVhs}$. After IEF the IPG strips were equilibrated in Tris-HCl buffer $\mathrm{pH} 8.8$, containing $6 \mathrm{M}$ urea, $2 \%(\mathrm{w} / \mathrm{v})$ SDS and $1 \%(\mathrm{w} / \mathrm{v})$ DTT, 30\% (w/v) glycerol. Second step of equilibration was performed in the same buffer as before but containing 4\% (w/v) iodoacetamide (Görg et al., 1988). After separation, protein spots were detected with colloidal Coomassie Brilliant Blue G-250 staining (Neuhoff et al., 1988). Protein patterns were compared and protein spots with different intensity were excised and used for mass spectrometry analyses. A detailed description of the whole progress of the MS analysis is available as a Supplementary material.

\subsection{Virus overlay protein binding assay (VOPBA)}

VOPBA was carried out following the protocol detailed in Jindadamrongwech and Smith (2004) (Jindadamrongwech and Smith, 2004). The gently purified virion extracts were resolubilized in Rabilloud-buffer and separated by SDS-PAGE on $12 \%$ gels. Semi-dry transfer of proteins to PVDF membranes was done in Anode I $(0.3 \mathrm{M}$ Tris, $10 \% \mathrm{MeOH}$ at $\mathrm{pH} 10.4$ ), Anode II (25 mM Tris, $10 \% \mathrm{MeOH}$ at $\mathrm{pH}$ 10.4) and Cathode ( $25 \mathrm{mM}$ Tris, $40 \mathrm{mM}$ Glycine, $10 \% \mathrm{MeOH}$ at 9.4 ) buffers, respectively. After transferring, the membranes were incubated with $50 \mu \mathrm{g}$ of highly purified mutant CMV virions per membrane in TBST with 5\% casein hydrolysate for two hours at room temperature. Then, membranes were washed with TBST and MQ water and incubated with CMV primary IgG antibody (Bioreba, Switzerland) at a dilution of 1:1000 in 5\% casein hydrolysate in TBST. After two $10 \mathrm{~min}$ long washes with TBST and MQ water the membranes were incubated with HRP-conjugated goat anti-rabbit IgG (Agrisera, Sweden) secondary antibody at a dilution of 1:5000 in 5\% casein hydrolysate in TBST for an hour at room temperature. Detection of virus-host protein interactions was performed with Pierce ECL Western Blotting Substrate (Thermo Scientific). Imaging was performed using Fujifilm Medical XRay Film.

\subsection{Virus binding affinity determination with modified ELISA experiments}

\subsubsection{Used materials}

$350 \mathrm{~g}$ of fresh and healthy Nicotiana clevelandii leaves were used for purification of ATP synthase F1 complex. According to former protocols (Groth and Schirwitz, 1999), ATP synthase F1 complex was released from isolated thylakoid membranes using EDTA treatment. After this, a single anion exchange chromatography step was carried out to obtain highly pure, homogenous $N$. c. ATP synthase F1 complex. Previously prepared highly purified wild type (R-CMV) and mutant (CMVR3E79R) virus samples were used for the modified ELISA experiments. The other reagents were the part of the official Bioreba CMV-DAS ELISA kit.

\subsubsection{Modified ELISA description}

Corning 96-well plate was used for the modified ELISA experiments. Triple technical replication was applied for each virus. Rows A, B and C belonged to the wild type CMV; row D was empty, while rows E, F and $\mathrm{G}$ belonged to the mutant CMV. Two-fold dilution series with six points were prepared from highly purified virus stock solutions. The seventh wells were the negative controls. In the first step, 50-fold dilution was created from the N. c. ATP synthase F1 (F1) stock solution $(0.11 \mathrm{mg} / \mathrm{ml})$ with the coating buffer (Sodium-carbonate buffer $\mathrm{pH}$ 9). $200 \mu$ l diluted F1 solutions were loaded to each well except the seventh wells because these were the negative controls. The plate was incubated at $4{ }^{\circ} \mathrm{C}$ overnight. After immobilization of the F1 complex, the plate was washed 4 times with PBST buffer. In the second step, the virus dilution series were loaded in Bioreba sample buffers. The concentration of the virus stock solutions were adjusted to $10.3 \mathrm{mg} / \mathrm{ml}$ and the following 
two-fold dilutions series were used in columns 1-6: $200 \times, 400 \times$, $800 \times, 1600 \times, 3200 \times$ and 6400 times dilutions of virus samples. $200 \mu \mathrm{l}$ samples were loaded per well and incubated at $4{ }^{\circ} \mathrm{C}$ overnight. After virus binding, the plate was washed 4 times with TBST. In the third step, alkaline phosphatase conjugated CMV antibody (Bioreba) was incubated at $1000 \times$ dilution in conjugate buffer. $200 \mu$ samples were loaded per well and incubated at $4{ }^{\circ} \mathrm{C}$ overnight. After conjugate antibody binding, the plate was washed 4 times with PBST. The last step was the colour reaction of the substrate pNPP (paraNitrophenylphosphate) with conjugated alkaline phosphatase. $200 \mu 1$ $1 \mathrm{mg} / \mathrm{ml} \mathrm{pNPP}$ in substrate buffer was added to each well and incubated at room temperature in dark.

\subsubsection{Data reading and evaluation}

According to the manufacturer recommendation the optimal reading time is $30-120 \mathrm{~min}$ after pNPP incubation. Absorbance data were read five times (at $30 \mathrm{~min}$ period) after pNPP incubation at $405 \mathrm{~nm}$ with a Thermo Scientific multiskan FC microplate reader. Data reads of two hours after pNPP incubation proved to be the best for data evaluation. The absorbance data were averaged and the average background (negative control) values were subtracted from them. These values were plotted as a function of virus concentration. The plots seemed classical sigmoidal saturation curves therefore non-linear fit could be used to extract the main parameters. The Logistic parameter fitting function was used in the Origin 8.5 software. The inflection point of the sigmoidal saturation curve (x0 parameter) has a biological meaning. This IC50 value is the half maximal effective concentration. These values were used to characterize the binding affinities of the wild and the mutant CMV to the N.c. ATP synthase F1 complex.

\subsection{Immunogold localization and electron microscopy}

Leaf segments of healthy or wild or mutant type CMV infected Nicotiana clevelandii plants were fixed in $10 \mathrm{mM}$ phosphate buffer (PB, $\mathrm{pH} 7.2)$ containing $4 \%(\mathrm{w} / \mathrm{v})$ paraformaldehyde for $4 \mathrm{~h}$ at $4{ }^{\circ} \mathrm{C}$ following gently vacuum infiltration. The samples were then rinsed three times in PB, dehydrated through a gradient series of ethanol at $4{ }^{\circ} \mathrm{C}$, and infiltrated with hard grade LR White resin according to the manufacturer's instructions (London Resin Ltd., Reading, England). Finally, they were polymerized at $50{ }^{\circ} \mathrm{C}$ for $48 \mathrm{~h}$. Ultrathin sections $(70 \mathrm{~nm})$ were cut from three blocks per treatment using an Ultracut $\mathrm{E}$ microtome (Reichert-Jung, Vienna, Austria) and mounted on Formvar-coated (SPIChem, West Chester, PA) 100-mesh nickel grids, three grids from each block.

Immunogold labelling was carried out by floating the grids on $30-\mu \mathrm{L}$ droplets of various solutions needed for the labelling as follows. Free aldehyde groups were blocked by $50 \mathrm{mM}$ glycine for $15 \mathrm{~min}$ in phosphate buffered saline (PBS, $10 \mathrm{mM}$ Na-phosphate buffer, $150 \mathrm{mM} \mathrm{NaCl}$, $\mathrm{pH}$ 7.4). Sections were then blocked with blocking solution containing $5 \%(\mathrm{w} / \mathrm{v})$ bovine serum albumin (BSA), $0.1 \%(\mathrm{w} / \mathrm{v})$ cold fish skin gelatine and $2 \%(\mathrm{v} / \mathrm{v})$ normal goat serum in PBS for $30 \mathrm{~min}$ at room temperature (RT).

For co-localization of the ATP synthase or Rubisco large subunit and the CMV double-labelled samples were created. Here the primary antibodies raised in chicken against beta subunit of ATP synthase or Rubisco large chain and raised in rabbit against CMV were mixed and then sections incubated for overnight. After that, the sections were incubated with a mix of 6 and $10 \mathrm{~nm}$ IgG-gold conjugate secondary antibody solutions at 1:30 dilution for $2 \mathrm{~h}$. The $6 \mathrm{~nm}$ gold conjugated goatanti-rabbit IgG (Aurion 806.011) indicates the CMV localization while the $10 \mathrm{~nm}$ gold conjugated goat-anti-chicken IgG (Aurion 810.244) reveals the ATP synthase beta subunit (Agrisera AB, AS03 030) or Rubisco large chain (Agrisera AB, AS01 017) localization. After all incubations with antibodies, the grids were washed six times for $5 \mathrm{~min}$ on PBS containing BSA-C. The unstained double-labelled sections were examined using a Hitachi 7100 transmission electron microscope (TEM) at $75 \mathrm{kV}$ accelerating voltage. Label frequency for CMV, ATP synthase beta subunit, Rubisco large chain and their co-localization was measured in 25 micrographs per sample using AnalySiS Pro 3.2 software in Touch Count mode (Soft Imagine System GmbH, Olympus, Tokyo, Japan) and data analysed in Excel (Microsoft, Redmond, USA).

\subsection{Molecular modelling and graphics}

All protein model structures were refined with the MacroModel energy minimization module of the Schrödinger Suite (Schrödinger, 2016) to eliminate the steric conflicts between the side-chain atoms. Previously generated CMV-R and CMV-R3E79R partial virion surfaces were subjected to protein-protein docking calculations as receptor partners. These partial virion surfaces were assembled from $27 \mathrm{CP}$ monomers in such a manner where the partial virion surface contains an adjacent $\mathrm{CP}$ hexamer and a $\mathrm{CP}$ pentamer surrounded with one $\mathrm{CP}$ layer. Since, no partial or complete Nicotiana clevelandii protein sequences were available in the Uniprot database and furthermore, the PDB database did not contain Nicotiana structures for ATP synthase alpha and beta subunits. Therefore, the closest MS hit, Nicotiana tabacum ATP synthase alpha (Uniprot id: P00823 (ATPA_TOBAC)) and beta (P00826 (ATPB_TOBAC)) subunit structures were built by the ITASSER protein structure prediction server (Zhang, 2008)(Roy et al., 2010). The hexamer Nicotiana tabacum (NT) ATP synthase F1 complex was constructed with Schrödinger Suite using the coordinates of the spinach ATP synthase F1 complex (PDB id: 1FX0) as reference structure. This NT ATP synthase F1 complex was used as ligand in the protein-protein docking calculations. Protein-protein docking calculations were carried out with the ClusPro 2.0 application (available online at https://cluspro.bu.edu/home.php) (Kozakov et al., 2013, 2006). In order to achieve optimal docking results repulsion masks were applied at the inner side of the partial virion structures and the top side of the ATP synthase F1 complex which is close to the membrane buried F0 complex. Electrostatic potential maps were calculated with Adaptive Poisson-Boltzmann Solver (APBS) version 1.3 (Baker et al., 2001) using the linearized Poisson-Boltzmann method (Gilson et al., 1987) with a dielectric constant of 78.0 and 2 for the water solvent and protein core, respectively. The partial charges for the electrostatic potential calculations were calculated with PDB2PQR (Dolinsky et al., 2004). Molecular graphics were created with VMD version 1.9.2 (Humphrey et al., 1996).

\section{Results}

Previously, we had created several CP mutants of a subgroup II CMV strain the CMV-R and one of them showed remarkable differences in symptom induction on Nicotiana clevelandii (Salánki et al., 2011). Infection with CMV-R caused only mild mosaic symptoms on $N$. clevelandii test plant while the mutant CMV-R3E79R virus induced chlorotic spots on the inoculated leaves and severe systemic symptoms, progressed/ resulted in tissue necrosis and plant death (Fig. 1).

\subsection{Host protein identification with mass spectrometry}

To investigate the cause of this strong phenotypic difference in symptoms, virions of both strains were subjected to a gentle purification in order to identify the interacting plant proteins that co-purified with CMV particles. Protein extracts obtained from three replicate purifications of virions were subjected to two-dimensional gel electrophoresis followed by LC-MS-MS analyses. The protein patterns of the samples resulted in reproducible differences in both the number and the intensity of the protein spots. The main differences were detected in the region of $\mathrm{pH} \mathrm{5-8}$ and in the 50-75 $\mathrm{kDa}$ regions (Fig. 2). Virion samples purified from CMV-R3E79R showed more intense staining of proteins in that region. In contrast, proteins detected in the $\mathrm{pH} 9$ and $25 \mathrm{kDa}$ region were more concentrated in the CMV-R samples. More than two-fold the 


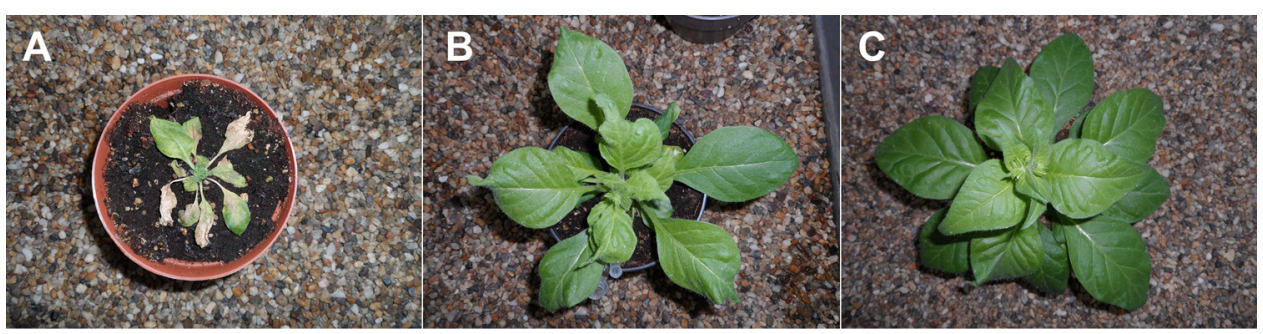

Fig. 1. Nicotiana clevelandii plants infected with mutant CMV-R3E79R (A) and wild type CMV-R (B) and a mock inoculated plant (C).

amount of protein spots occurred with the CMV-R3E79R than with the CMV-R strain. Twenty spots showing intensity differences were excised from the gels and subjected to mass spectrometry analysis (Table 1). Peptide hits from the mutant virion's gel were used for BLAST analyses against the genus Nicotiana. Since, the $N$. clevelandii genome is still unknown, the most relevant hits against the peptide sequences were identified from other Nicotiana species e.g. N. undulata, N. plumbaginifolia, $N$. tabacum and N. sylvestris (Table 1). The majority of the identified peptides belonged to the alpha or beta subunits of ATP synthase located in the chloroplast and in the mitochondria. Furthermore, a few hits were identified as the large or small subunits of Rubisco located in chloroplast. In one case, ATP synthase beta (spot number 6) showed the highest sequence homology to an ATP synthase subunit beta located in the chloroplast of Nicotiana plumbaginifolia. Spots numbered 7, 8, 10, 14 represented alpha subunits, while spots $2,3,4,5,6,12$ were beta subunits. Spots numbered 1, 9, 11, 13 were identified as Rubisco large subunits while spots numbered $16,17,18$ and 19 were small subunits of Rubisco, respectively. Protein spots 15 and 20 were identified as CMV CP (Table 1). All identified ATP synthase subunits possessed molecular weights in a range of 46-60 kDa with isoelectric points (pI) of pH 5-8, which corresponds to the calculated molecular weights and isoelectric points of known ATP synthase alpha and beta subunits of other $\mathrm{Ni}$ cotiana species. The appearance of the same subunit at different isoelectric points reflects the various phosphorylation states of the given protein.

\subsection{Virus overlay protein binding assay}

VOPBA was carried out to prove the direct interactions between host plant proteins and the virus particles. Three positive bands were detected in both lane (Fig. 3). Signals at the position of alpha and beta subunits of ATP synthase were much intense in the first lane which belonged to the gently purified mutant virus sample. These data are in correspondence with the $2 \mathrm{D}$ gels since the same gently purified virus samples were also used here. The higher ATP synthase bands belongs to the larger beta subunit (approx. $59 \mathrm{kDa}$ ) while the other ATP synthase bands indicate the smaller alpha subunit (approx. $55 \mathrm{kDa}$ ). The lowest intense bands obviously cover the CMV capsid proteins (approx. $25 \mathrm{kDa}$ ). This means that the separate capsid proteins bind very well the used virion probe but the intensity values of the VOPBA cannot be used for quantitative analysis because the imaging film had to be overexposed in order to make visible the localizations of the ATP synthase subunits. Furthermore, with this overexposure the accumulation level of the CMV CP seems to be much higher than in the 2D gels (Figs. 2 and 3). Unfortunately, the above mentioned limitations of this method didn't allow the quantitative characterization of CMV binding to ATP synthase. Therefore, we developed a modified ELISA experiments so as to achieve this goal.

\subsection{Virus binding affinity determined by modified ELISA}

Modified ELISA experiment was designed in order to reveal the binding affinity of the wild-type and mutant CMV to the $N$. $c$. ATP synthase F1 complex (Fig. 4). Isolated $N$. c. ATPase F1 complex was immobilized to the ELISA plate in this modified ELISA experiment. The second layers were highly purified wild-type CMV and mutant CMV dilution series and a negative control. The third layer was an alkaline phosphatase conjugated anti-CMV antibody (Bioreba). The expected result had been got after non-linear sigmoidal parameter fitting: the mutant CMV binds almost four times stronger the ATP synthase F1 complex than the wild virus. The EC50 value is $65.04 \mu \mathrm{g} / \mathrm{ml}$ for the wild-type CMV while it is $17.42 \mu \mathrm{g} / \mathrm{ml}$ for the mutant CMV.

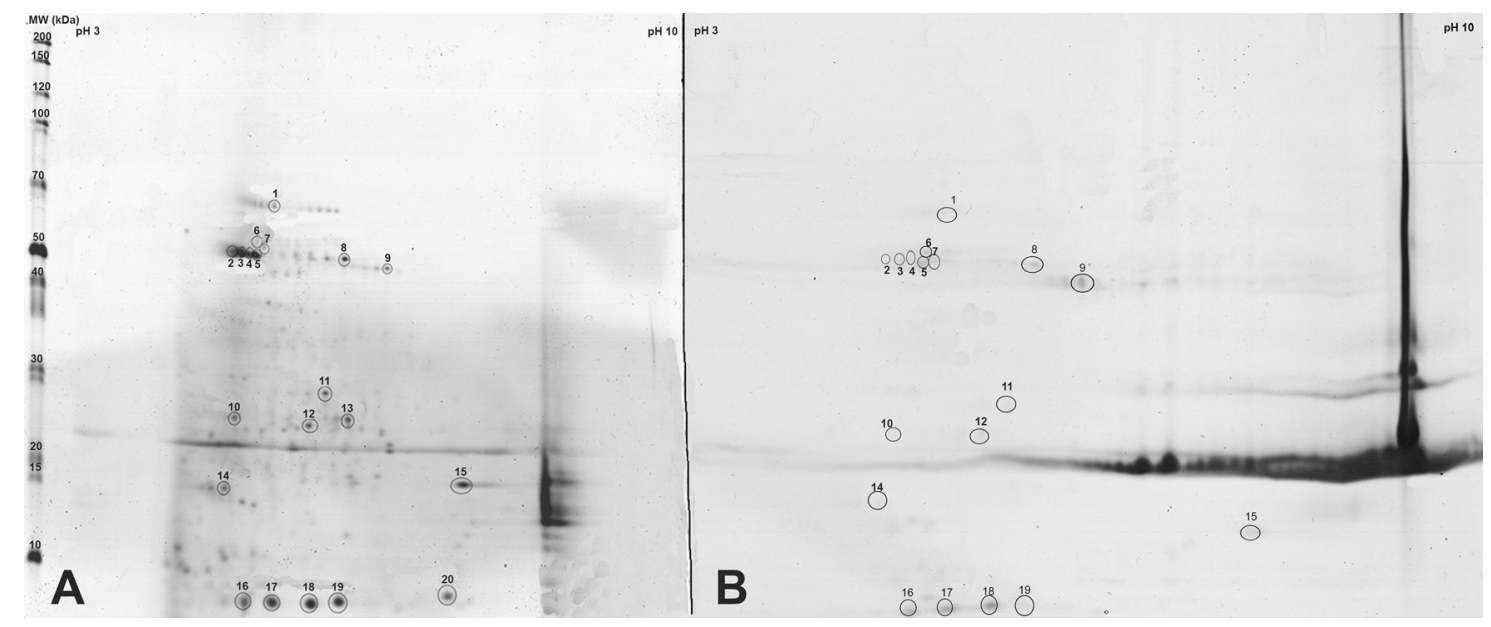

Fig. 2. Two dimensional gels stem from the gently purified virus samples. Gel (A) represents the protein pattern of the mutant virus (CMV-R3E79R) while gel (B) belongs to the wild type virus (CMV-R). Proteins were separated on 3-10 pH IPG strips followed by separation on $12 \%$ polyacrylamide gels. Proteins identified by mass spectrometry are circled and labelled by numbers. It is well visible from the spot intensities that the mutant virus binds more host proteins than the wild type virus. 
Table 1

Result of mass spectrometry of the protein spots.

\begin{tabular}{|c|c|c|c|c|c|c|c|}
\hline Spot number & UniProt ID & Protein name & Organism & Theoretical MW & Theoretical pI & Mascot Score & Subcellular localization \\
\hline 1 & G3LV08 & Rubisco large chain & Nicotiana undulata & 52912 & 6.29 & 126,48 & Chloroplast \\
\hline 2 & P17614 & ATP synthase subunit beta, & Nicotiana plumbaginifolia & 59856 & 5.95 & 1066 & Mitochondrion \\
\hline 3 & P17614 & ATP synthase subunit beta, & Nicotiana plumbaginifolia & 59856 & 5.95 & 1066 & Mitochondrion \\
\hline 4 & P17614 & ATP synthase subunit beta, & Nicotiana plumbaginifolia & 59856 & 5.95 & 1327 & Mitochondrion \\
\hline 5 & P17614 & ATP synthase subunit beta, & Nicotiana plumbaginifolia & 59856 & 5.95 & 1082 & Mitochondrion \\
\hline 6 & P17614 & ATP synthase subunit beta & Nicotiana plumbaginifolia & 59856 & 5.95 & 260 & Chloroplast \\
\hline 7 & Q5M9V4 & ATP synthase subunit alpha, & Nicotiana tabacum & 55323 & 5.84 & 121 & Mitochondrion \\
\hline 8 & Q5M9V4 & ATP synthase subunit alpha & Nicotiana tabacum & 55323 & 5.84 & 930 & Mitochondrion \\
\hline 9 & P00876 & Rubisco large chain; & Nicotiana tabacum & 52898 & 6.29 & 534 & Chloroplast \\
\hline 10 & P05495 & ATP synthase subunit alpha & Nicotiana plumbaginifolia & 55225 & 5.84 & 293 & mitochondrion \\
\hline 11 & G3LV08 & Rubisco large chain; & Nicotiana undulata & 52912 & 6.13 & 161 & Chloroplast \\
\hline 12 & Q9SAQ0 & ATP synthase subunit beta; & Nicotiana sylvestris & 59520 & 5.73 & 351 & Mitochondrion \\
\hline 13 & G3LV08 & Rubisco large chain & Nicotiana undulata & 52912 & 6.29 & 548 & Chloroplast \\
\hline 14 & Q5M9V4 & ATP synthase subunit alpha, & Nicotiana tabacum & 55323 & 5.84 & 143 & Mitochondrion \\
\hline 15 & Q66124 & Capsid protein & Cucumber mosaic virus & 24173 & 9.81 & 111 & Virion \\
\hline 16 & P22433 & Rubisco small chain; & Nicotiana sylvestris & 20474 & 6.59 & 388 & Chloroplast \\
\hline 17 & P22433 & Rubisco small chain & Nicotiana sylvestris & 20474 & 6.59 & 394 & Chloroplast \\
\hline 18 & P22433 & Rubisco small chain & Nicotiana sylvestris & 20474 & 6.59 & 496 & Chloroplast \\
\hline 19 & P22433 & Rubisco small chain & Nicotiana sylvestris & 20474 & 6.59 & 223 & Chloroplast \\
\hline 20 & P24147 & Capsid protein & Cucumber mosaic virus & 24202 & 9.92 & 297 & Virion \\
\hline
\end{tabular}

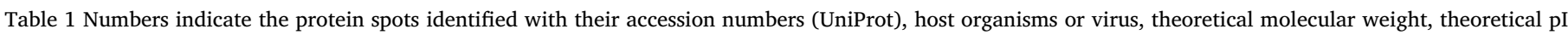

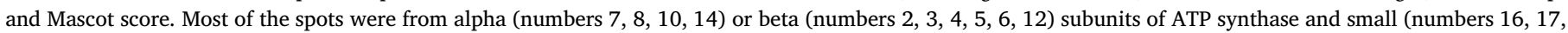

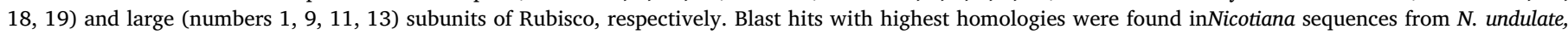

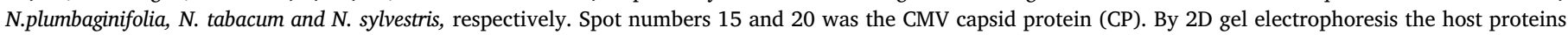
were found in the range of $\mathrm{pH} 5-8$ and $\mathrm{CP}$ were identified at $\mathrm{pH}$. The spots are indicated on the 2D gels.

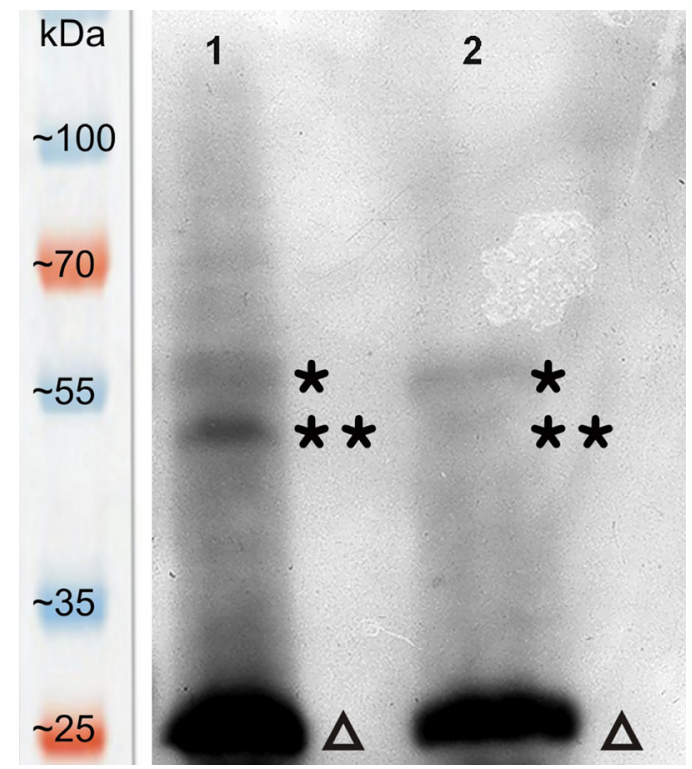

Fig. 3. Virus overlay protein binding assay (VOPBA). This experiment was carried out in order to confirm the direct interaction between ATP synthase subunits and the CMV. The gently purified mutant virus sample was separated in the 1st lane while the wild type sample in the 2nd lane, respectively. Positive bands with one star indicate the ATP synthase subunit beta (approx. $59 \mathrm{kDa}$ ) and bands with two stars were identified as ATP synthase subunit alpha (approx. $55 \mathrm{kDa}$ ). Thick bands indicated by triangles at $25 \mathrm{kDa}$ represent the interaction between the separated capsid protein monomers $(25 \mathrm{kDa})$ and the purified CMV virions.

\subsection{Immunoelectron microscopy}

TEM micrographs serve clear evidence for that the CMV not only localises in the cytoplasm (viroplasm) but it can also be found in the chloroplast. To estimate co-localization of CMV and the ATP synthase F1 complex, and as a control the Rubisco large chain, in wild type and mutant CMV infected plants, we carried out double-labelled immunoelectron EM (Fig. 5). Staining background was characterized using control group where primary antibodies were omitted. Affinity of anti-ATP synthase and anti-Rubisco large chain antibodies was visualized in non CMV infected plants. The $6 \mathrm{~nm}$ in diameter gold particles indicated the virus localization while the $10 \mathrm{~nm}$ in diameter gold particles indicated the ATP synthase F1 complex or Rubisco large chain localization.

We found double-labelled regions in the chloroplast, but the difference in frequency of their occurrence seemed to be not significant between the wild-type and the mutant virus infected samples. However, detailed measurements showed about three times higher co-localization of mutant virus with ATP synthase than in case of wild type virus (Fig. 6). Localization frequency was higher but unchanged in Rubisco large chain labelled CMV infected plants. Here we found continuous distribution of 6 and $10 \mathrm{~nm}$ gold particles in the chloroplast stroma without close co-localization. In fact, it was proportionally comparable with co-localization seen in ATP synthase labelled wild type CMV infected samples.

We assume that the difference in ATP synthase and mutant CMV colocalization affinity data gained by morphometry and modified ELISA (about 3 versus almost 3.8, respectively) is because there is a steric hindrance which blocks to some extent binding of the $10 \mathrm{~nm} \mathrm{IgG-gold}$ conjugate secondary antibody to the F1 complex (Fig. 5D and L). Namely, the anchored CMV virion may not let enough space for the $10 \mathrm{~nm}$ IgG-gold conjugate secondary antibody against ATP synthase.

\subsection{Protein-protein dockings support the experimental results}

Protein-protein docking calculations clearly support the experimental results (Fig. 7). Partial virion surfaces were used as receptors while Nicotiana tabacum ATP synthase F1 complex models as ligands in protein-protein docking calculations. The electrostatic-favoured weighted docking scores of the best docking clusters were used in the comparison of the wild and mutant CMV because of the nature of the amino acid change (E/79/R) (Fig. 7A and B). These changes in the electrostatic surface potential caused by the $\mathrm{E} / 79 / \mathrm{R}$ mutation are clearly visible on Fig. 7C and D. Due to the high memory usage, the electrostatic surface potential of the virions were calculated only for an adjacent $\mathrm{CP}$ hexamer and pentamer which are the building blocks of the truncated icosahedral CMV particle. 
Wild type CMV binding affinity to immobilized $N$. c. ATP synthase F1 complex

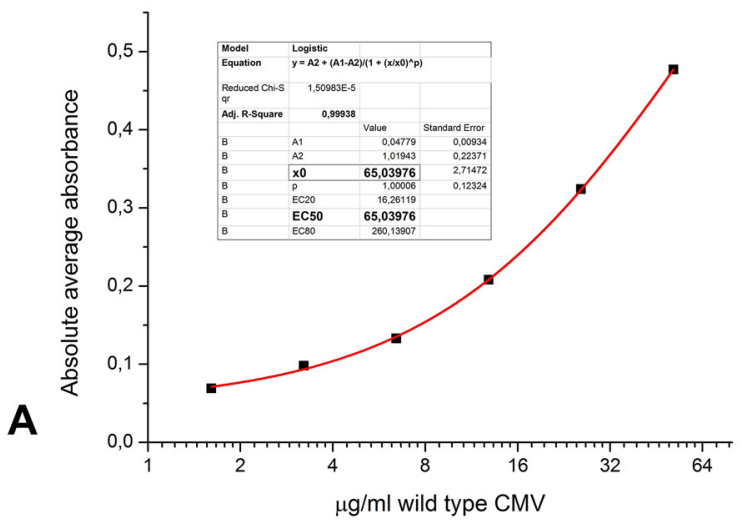

C

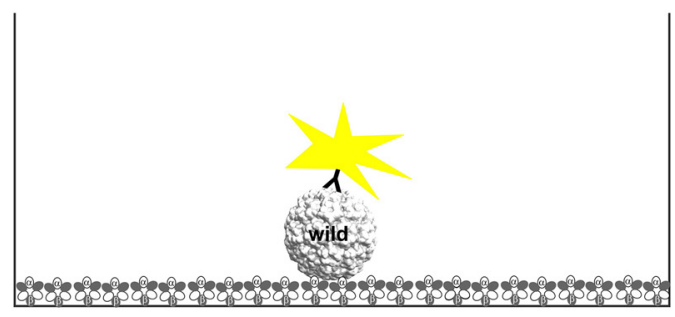

Mutant CMV binding affinity to immobilized $N$. c. ATP synthase F1 complex

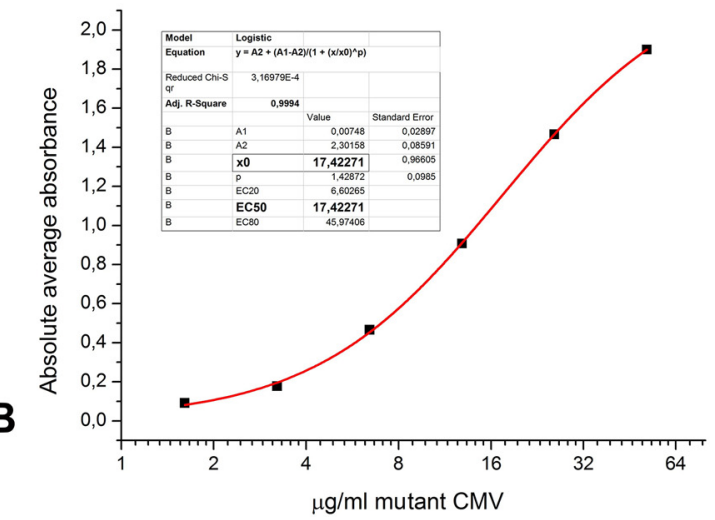

D

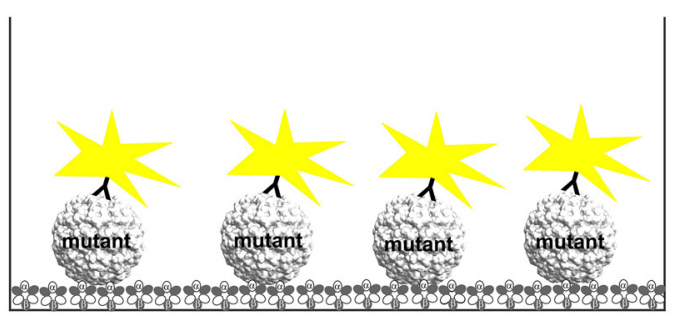

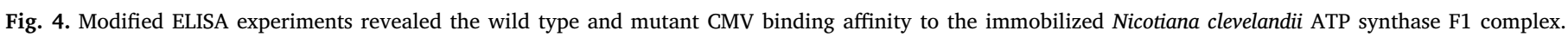

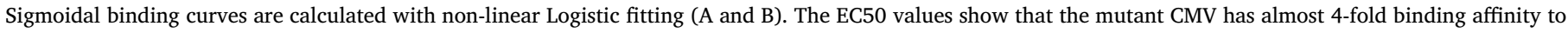
the ATP synthase F1 complex than the wild type CMV has. The experimental setup of the modified ELISA experiments are indicated in panels C and D.

\section{Discussion}

Plant proteins have essential roles in the life cycle of the viral pathogen. They influence virus accumulation and symptom development, however their roles in defence response needs further elucidation. A few examples were collected where host-virus protein interactions were in the focus. In the case of tobacco mosaic virus (TMV) two nuclearencoded chloroplast proteins were purified with virus replication complexes and viral polymerase from the Nicotiana sp. following the TMV-host pathogen interaction (Bhat et al., 2013). Protein-protein interactions of TMV and the Nicotiana host plant were confirmed by sequences of cDNAs from a tobacco library and identifying the essential function of a host protein in systemic movement of TMV (Li et al., 2005). The necrotic reactions of plant cells are mediated by a sustained burst of reactive oxygen species (ROS) (Lamb and Dixon, 1997) and followed by salicylic acid accumulation both in the infected cells and at distal part of the plants (Malamy et al., 1990). These fundamental observations are the basis of the salicylic acid induced resistance to pathogens (Murphy et al., 1999) which involves the increased activities of different enzymes present in the infected plant tissue. It was reported that activity of various antioxidant enzymes were suppressed during response to salicylic acid, while activity of ROS generating enzymes increased (Mittler, 2002). It was also demonstrated that silencing of a gene encoding a protein component of the oxygen evolving complex of photosystem II increased the replication of TMV in tobacco plants (Abbink et al., 2002). Based on the studies of Seo and co-workers (Seo et al., 2014) chloroplast-encoded ATP synthase beta induced tissue necrosis in $N$. benthamiana and also in Arabidopsis thaliana infected with Alternanthera mosaic virus (AltMV). However, when virus induced gene silencing was performed, expression of ATP synthase subunit beta was reduced. They summarized that chloroplast ATP synthase beta subunit is not required for AltMV movement and replication but silencing of chloroplast ATP synthase beta caused severe tissue necrosis when tobacco plants were infected by AltMV (TGB1L88) but not AltMV (TGB1P88), suggesting that ATP synthase beta subunit selectively responded to the mutant AltMV (TGB1L88) to induce defence responses
(Seo et al., 2014).

In a previous study, we found that a single amino acid replacement on the CMV virion surface can cause drastic changes in symptoms expressed by the infected plant (Salánki et al., 2011). In this work our main goals were to identify the interacting host factors and characterize the molecular background of the above described unusual symptoms. Based on our results presented here, we hypothesise that the stronger electrostatic interaction introduced by glutamate to arginine mutation present in the CP of CMV-R3E79R can block the rotation of the F1 motor complex of ATP synthase, thereby inhibiting synthesis of ATP. These findings agree well with the early studies of Király and his coworkers describing the hypersensitive reaction, that tissue necrotization is not the cause, but is the consequence of plant disease resistance (Király et al., 1972).

Taken together the results of the VOPBA, the immunoelectron microscopy and the modified ELISA experiments have confirmed the direct interactions between the mutant CMV and $N$. clevelandii ATP synthase F1 motor complex. Our results suggest that mutant CMV (R3E79R) can bind and hold ATP synthase F1 complex on its surface with an increased strength and may be an essential player in the cell death and tissue necrotization. Furthermore, we assume that the difference in ATP synthase and mutant CMV co-localization affinity data gained by morphometry and modified ELISA (about 3 versus almost 3.8 , respectively) is because there is a steric hindrance which blocks to some extent binding of the $10 \mathrm{~nm}$ IgG-gold conjugate secondary antibody to the F1 complex (Fig. 5D and L). Namely, the anchored CMV virion may not let enough space for the $10 \mathrm{~nm} \mathrm{IgG-gold} \mathrm{conjugate}$ secondary antibody against ATP synthase. It is important to mention that the amino acid sequences of the $N$. clevelandii ATP synthase subunits are still unknown therefore we cannot specify that whether which ATP synthase residues responsible for the stronger interaction with the mutant CMV. Although the amino acid similarities of the known $\mathrm{Ni}$ cotiana ATP synthase alpha and beta subunits are almost 100\% (Supplementary material 2) a few mutations which cause electrostatic changes e.g. G/D or K/E have been detected among the known $\mathrm{Ni}$ cotiana ATP synthase beta subunits. So, it is possible that $N$. clevelandii 

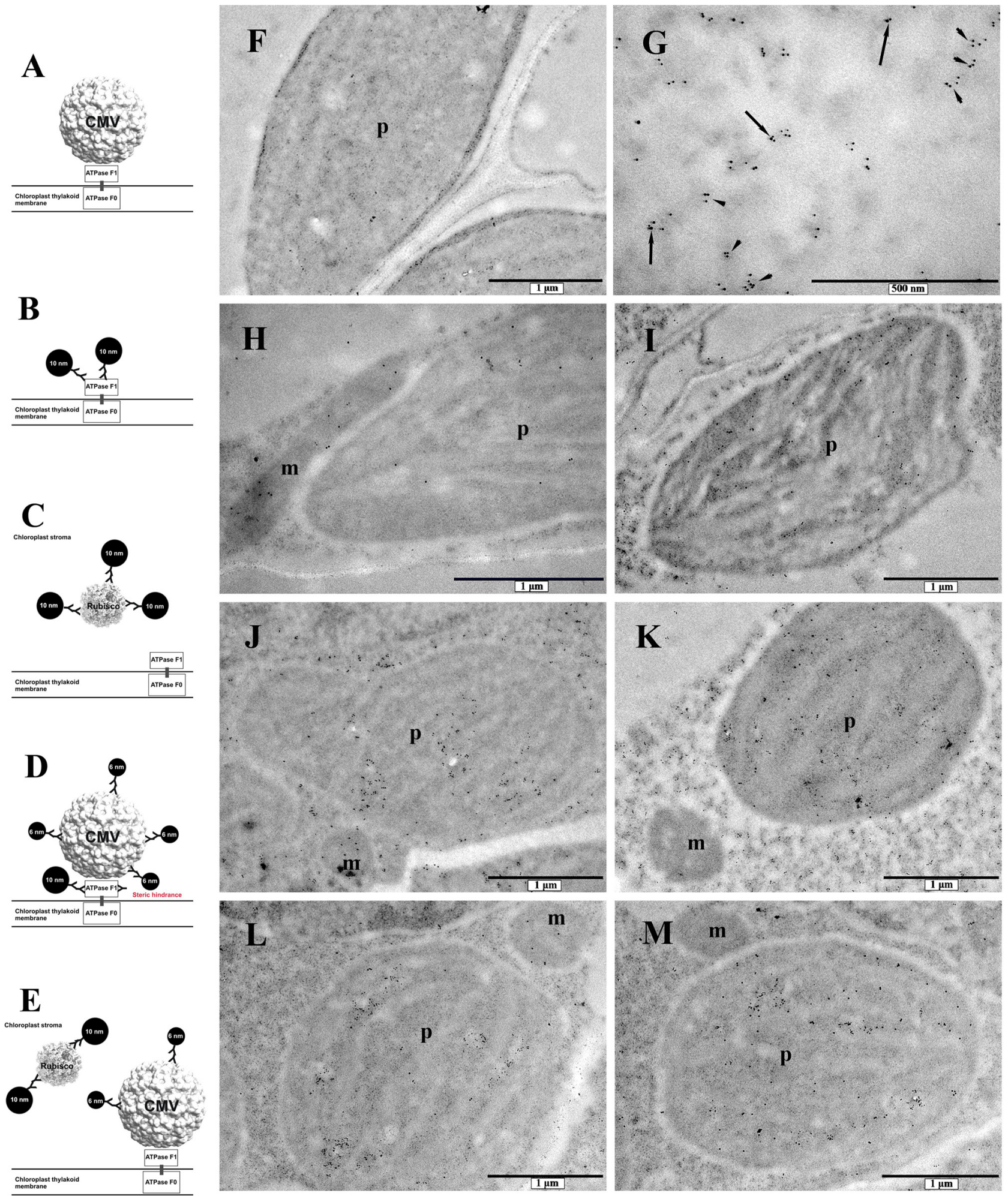

Fig. 5. Double-labelled immunogold detection of CMV and ATP synthase F1 beta subunit or Rubisco large chain. Diagrams (A-E) show the experimental setup. Micrographs (F-M) demonstrate representative details found in the samples. A: adhesion of non-labelled CMV to ATP synthase F1, B and C: $10 \mathrm{~nm}$ in diameter gold particles attached to ATP synthase F1 subunit beta or Rubisco large chain, respectively, D: binding of $10 \mathrm{~nm}$ IgG-gold conjugate to ATP synthase F1 subunit beta and $6 \mathrm{~nm}$ in diameter gold particles attached to CMV, E: $10 \mathrm{~nm}$ in diameter gold particle labelled Rubisco large chain and unstained ATP synthase F1 bound CMV where the virus capsid is labelled with $6 \mathrm{~nm}$ in diameter gold particles, F: negative control with omitted primary antibodies to show staining background, G: detail of a plastid with a higher magnification to show mutant CMV staining (arrowheads) and CMV and ATP synthase co-localization (arrows), H: result of double-staining against ATP synthase and CMV in uninfected plants, I: result of double-label against Rubisco large chain and CMV in uninfected plants, J: ATP synthase and CMV localization in wild type CMV infected plants, K: Rubisco large chain and CMV localization in wild type CMV infected plants, L: ATP synthase and CMV localization in mutant CMV infected plants, M: Rubisco large chain and CMV localization in mutant CMV infected plants. m: mitochondria, p: plastids. 

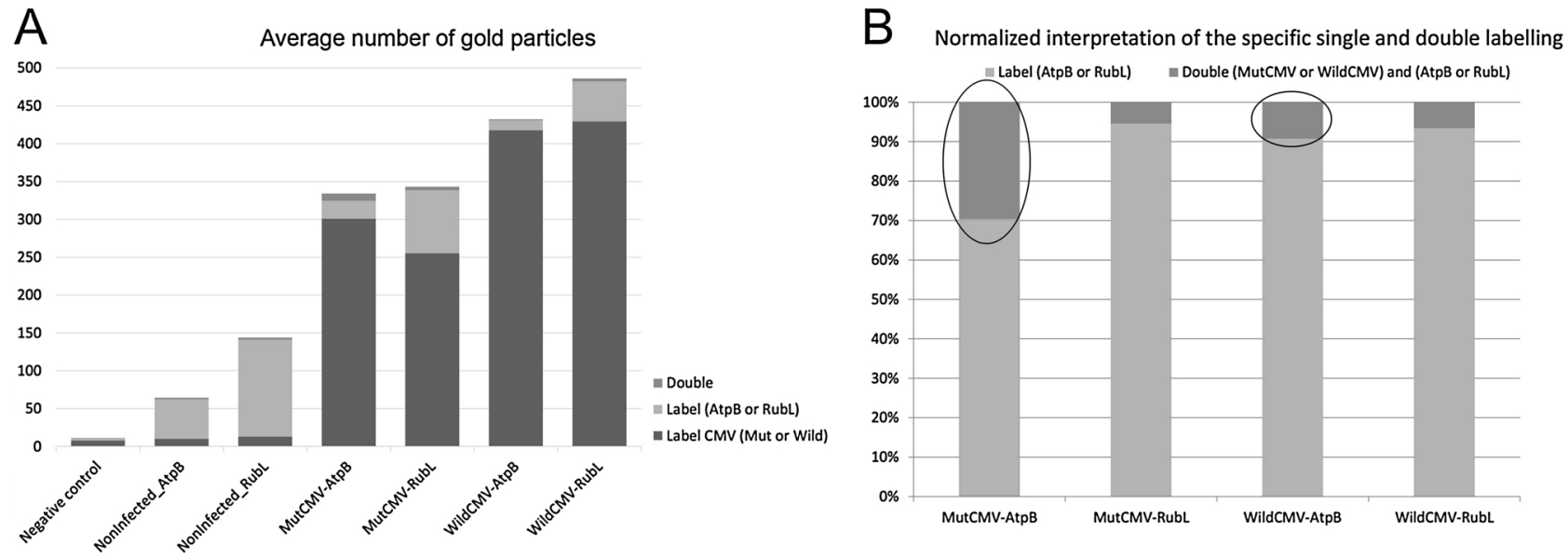

Fig. 6. Statistical evaluation of the TEM micrographs. Altogether seven type of experimental setups were used to characterise the co-localization of the wild and mutant CMV with the ATP synthase F1 complex or Rubisco. Panel A shows the average number of gold particles for each experimental setup while panel B presents the normalized interpretation of the specific single and double labelling. It is clearly visible from this diagram that the prevalence of co-localization between the mutant CMV and the ATP synthase is three times higher than in the case of wild-type CMV while significant difference is not detected in the case of mutant or wild CMV and Rubisco co-localization. For each experimental setup an EM micrograph can be seen on Fig. 5. Negative control: Fig. 5F, NonInfected_AtpB: Fig. 5H, NonInfected_RubL: Fig. 5I, MutCMV-AptB: Fig. 5L, MutCMV-RubL: Fig. 5M, WildCMV-AptB: Fig. 5J and WildCMV-RubL: Fig. 5K.

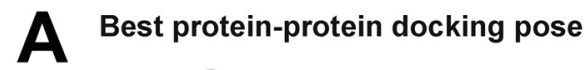

\section{B Best protein-protein docking pose}

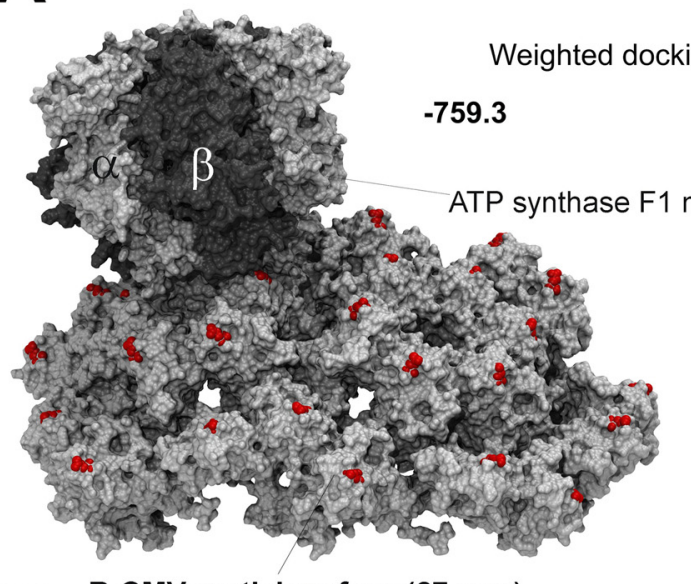

R-CMV partial surface (27-mer)

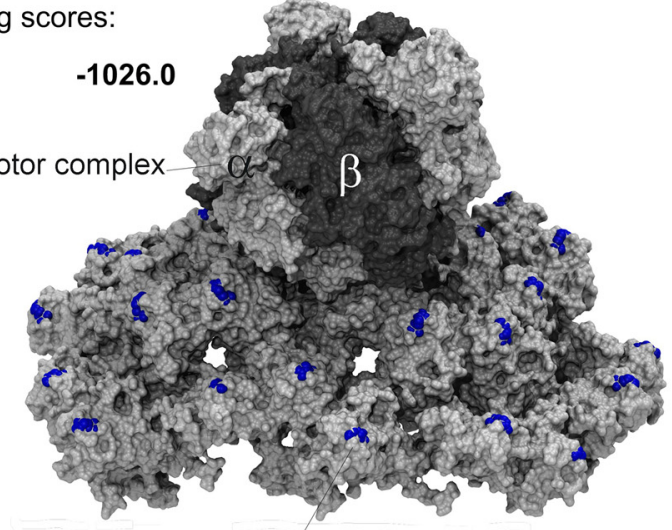

R3E79R mutant CMV partial surface (27-mer)

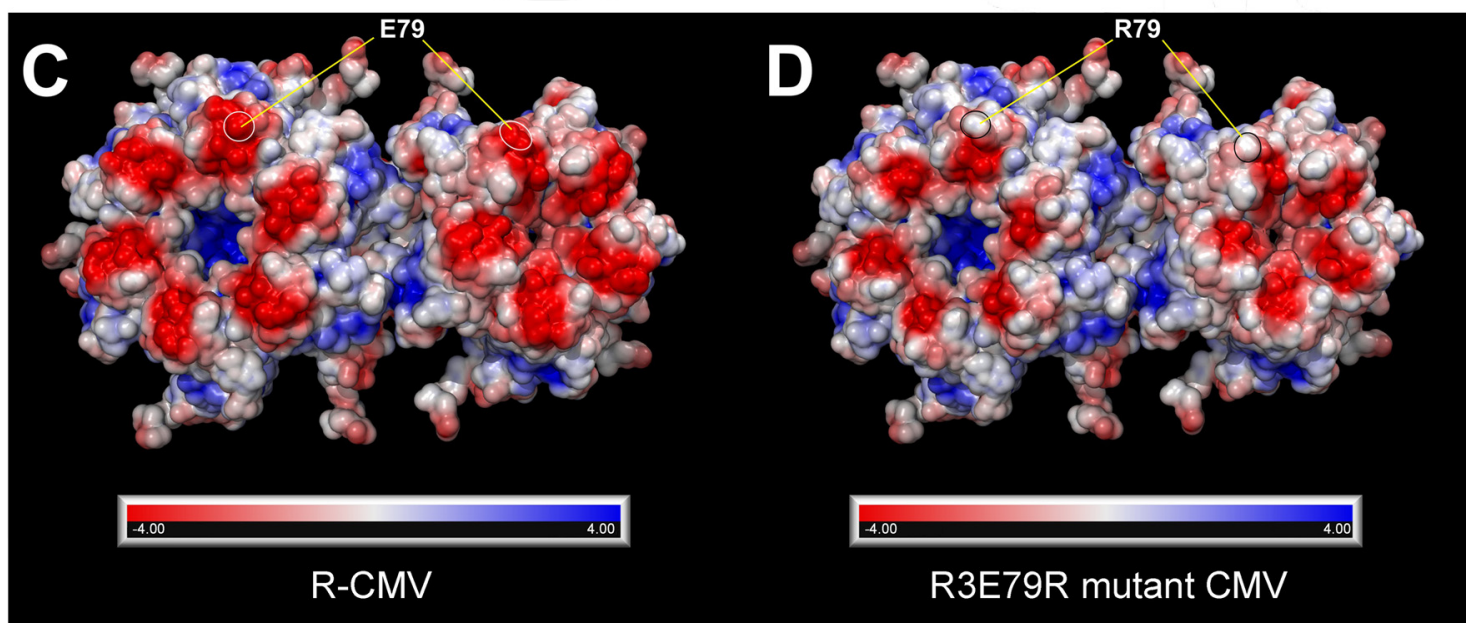

Fig. 7. Molecular background of the CMV-ATP synthase molecular interactions. The best protein-protein docking poses are in molecular surface representation (A and B). The electrostatic-favoured weighted docking scores of the best docking clusters are indicated in the figure. All E79 and R79 residues of the CMV capsid proteins are coloured red and blue on the surface of the viruses (A and B). The C and D panels show the electrostatic view of an adjacent coat protein hexamer and pentamer from the CMV virion surface. Red represents regions with potential value less than $-4.0 \mathrm{kT}$; white represents 0.0 ; blue shows regions greater than $+4.0 \mathrm{kT}$. Amino acids in position 79 are indicated in the CMV-R (C) and CMV-R3E79R (B) surfaces, respectively (For interpretation of the references to colour in this figure legend, the reader is referred to the web version of this article). 
ATP synthase subunits bear specific mutation(s) which play(s) a crucial role in the special interaction with the mutant CMV. Additional, protein-protein docking calculations demonstrated that the electrostatic interactions between the ATP synthase F1 motor complex and the mutant CMV surface are very strong due to the numerous salt bridges. Furthermore, this strong and invasive electrostatically driven proteinprotein aggregation finally leads to cell death suggesting that the plant cell cannot synthesize enough new ATP synthase subunits to replace those complexed or rendered inactive by the mutant CMV. On the other hand, the ATP synthase F1 motor complex did not bind to the wild-type CMV virions with the same strength due to the presence of negatively charged glutamate residues in the same position. These findings agree perfectly well with the aforementioned examples (Murphy et al., 1999) on high enzymatic activities observed during necrotization of the plant tissue, underlying that host proteins interactions with the infecting pathogens are essential in symptom formation.

\section{Acknowledgements}

Financial support was obtained from the National Research, Development and Innovation Office (Grant number 108793). Á.G. received a János Bolyai fellowship from the Hungarian Academy of Sciences.

\section{Appendix A. Supplementary data}

Supplementary material related to this article can be found, in the online version, at doi:https://doi.org/10.1016/j.virusres.2018.05.005

\section{References}

Abbink, T.E.M., Peart, J.R., Mos, T.N.M., Baulcombe, D.C., Bol, J.F., Linthorst, H.J.M., 2002. Silencing of a gene encoding a protein component of the oxygen-evolving complex of photosystem II enhances virus replication in plants. Virology 295, 307-319. http://dx.doi.org/10.1006/viro.2002.1332.

Baker, N.A., Sept, D., Joseph, S., Holst, M.J., McCammon, J.A., 2001. Electrostatics of nanosystems: application to microtubules and the ribosome. Proc. Natl. Acad. Sci. 98, 10037-10041.

Bhat, S., Folimonova, S.Y., Cole, A.B., Ballard, K.D., Lei, Z., Watson, B.S., Sumner, L.W., Nelson, R.S., 2013. Influence of host chloroplast proteins on tobacco mosaic virus accumulation and intercellular movement. Plant Physiol. 161, 134-147.

Boccard, F., Baulcombe, D., 1993. Mutational analysis of cis-acting sequences and gene function in RNA3 of cucumber mosaic virus. Virology 193, 563-578.

Dolinsky, T.J., Nielsen, J.E., McCammon, J.A., Baker, N.A., 2004. PDB2PQR: an automated pipeline for the setup, execution, and analysis of Poisson-Boltzmann electrostatics calculations. Nucleic Acid Res. 32, 665-667.

Gilson, M.K., Sharp, K.A., Honig, B., 1987. Calculating electrostatic interactions in biomolecules: method and error assessment. J. Comput. Chem. 9, 327-335.

Görg, A., Postel, W., Günther, S., 1988. The current state of two-dimensional electrophoresis with immobilized $\mathrm{pH}$ gradients. Electrophoresis 531-546.

Groth, G., Schirwitz, K., 1999. Rapid purification of membrane extrinsic F1-domain of chloroplast ATP synthase in monodisperse form suitable for 3D-crystallization. Eur. J. Biochem. 260, 15-21. http://dx.doi.org/10.1046/j.1432-1327.1999.00101.x.

Harrison, S.C., 1984. Multiple-modes of subunit association in the structures of simple spherical viruses. Trends Biochem. Sci. 9, 345-351. http://dx.doi.org/10.1016/09680004(84)90057-4.

Humphrey, W., Dalke, A., Schulten, K., 1996. Visual molecular dynamics. J. Mol. Graph. 14, 33-38.

Jindadamrongwech, S., Smith, D.R., 2004. Virus overlay protein binding assay (VOPBA) reveals serotype specific heterogeneity of dengue virus binding proteins on HepG2 human liver cells. Intervirology 47, 370-373. http://dx.doi.org/10.1159/ 000080882.

Király, Z., Barna, B., Érsek, T., 1972. Hypersensitivity as a consequence, not the cause, of plant resistance to infection. Nature 239, 456-458.
Kobori, T., Miyagawa, M., Nishioka, K., Ohki, S.T., Osaki, T., 2002. Amino acid 129 of cucumber mosaic virus coat protein determines local symptom expression and systemic movement in Tetragonia expansa, Momordica charanti and Physalis floridana. J. Gen. Plant Pathol. 68, 81-88.

Kozakov, D., Beglov, D., Bohnuud, T., Mottarella, S.E., Xia, B., Hall, D.R., Vajda, S., 2013. How good is automated protein docking? Proteins 81, 2159-2166.

Kozakov, D., Brenke, R., Comeau, S.R., Vajda, S., 2006. PIPER: an FFT-based protein docking program with pairwise potentials. Proteins 65, 392-406.

Lamb, C., Dixon, R.A., 1997. The oxidative burst in plant disease resistance. Ann. Rev. Plant Physiol. Plant Mol. Biol. 48, 251-275. http://dx.doi.org/10.1146/annurev. arplant.48.1.251.

Li, Y., Wu, M.Y., Song, H.H., Hu, X., Qiu, B.S., 2005. Identification of a tobacco protein interacting with tomato mosaic virus coat protein and facilitating long-distance movement of virus. Arch. Virol. 150, 1993-2008. http://dx.doi.org/10.1007/s00705005-0554-5.

Liu, S.J., He, X.H., Park, G., Josefsson, C., Perry, K.L., 2002. A conserved capsid protein surface domain of cucumber mosaic virus is essential for efficient aphid vector transmission. J. Virol. 76, 9756-9762. http://dx.doi.org/10.1128/jvi.76.19.97569762.2002.

Lot, H., Marrou, J., Quiot, J.B., Esvan, C., 1972. Contribution á l'étude du virus de la mosaique du concombre (CMV). I. Méthode de purification rapide du virus. Ann. Phytopathol. 4, 25-38.

Malamy, J., Carr, J.P., Klessig, D.F., Raskin, I., 1990. Salicylic acid: a likely endogenous signal in the resistance response of tobacco to viral infection. Science 250, 1002-1004.

Mittler, R., 2002. Oxidative stress, antioxidants and stress tolerance. Trends Plant Sci. 7, 405-410. http://dx.doi.org/10.1016/s1360-1385(02)02312-9.

Mochizuki, T., Ohki, S.T., 2011. Single amino acid substitutions at residue 129 in the coat protein of cucumber mosaic virus affect symptom expression and thylakoid structure. Arch. Virol. 156, 881-886.

Mochizuki, T., Ohki, S.T., 2005. Amino acid 129 in the coat protein of cucumber mosaic virus primarily determines invasion of the shoot apical meristem of tobacco plants. J. Gen. Plant Pathol. 71, 326-332.

Murphy, A.M., Chivasa, S., Singh, D.P., Carr, J.P., 1999. Salicylic acid-induced resistance to viruses and other pathogens: a parting of the ways? Trends Plant Sci. 4, 155-160. http://dx.doi.org/10.1016/s1360-1385(99)01390-4.

Neuhoff, V., Arold, N., Taube, D., Ehrhardt, W., 1988. Improved staining of proteins in polyacrylamide gels including isoelectric-focusing gels with clear background at nanogram sensitivity using coomassie brilliant blue G-250 and R-250. Electrophoresis 9, 255-262. http://dx.doi.org/10.1002/elps.1150090603.

Palukaitis, P., García-Arenal, F., 2003. Cucumoviruses. Adv. Virus Res. 62, 241-323.

Palukaitis, P., Roossinck, M.J., Dietzgen, R.G., Francki, R.I., 1992. Cucumber mosaic virus. Adv. Virus Res. 41, 281-348.

Park, M.-R., Park, S.-H., Cho, S.-Y., Kim, K.-H., 2009. Nicotiana benthamiana protein, NbPCIP1, interacting with potato virus X coat protein plays a role as susceptible factor for viral infection. Virology 386, 257-269.

Qiu, Y., Zhang, Y., Wang, C., Lei, R., Wu, Y., Li, X., Zhu, S., 2018. Cucumber mosaic virus coat protein induces the development of chlorotic symptoms through interacting with the chloroplast ferredoxin I protein. Sci. Rep. 8, 1205. http://dx.doi.org/10.1038/ s41598-018-19525-5.

Rabilloud, T., Adessi, C., Giraudel, A., Lunardi, J., 1997. Improvement of the solubilization of proteins in two-dimensional electrophoresis with immobilized $\mathrm{pH}$ gradients. Electrophoresis 18, 307-316. http://dx.doi.org/10.1002/elps.1150180303.

Roy, A., Kucukural, A., Zhang, Y., 2010. I-TASSER: a unified platform for automated protein structure and function prediction. Nat. Protoc. 5, 725-738.

Ryu, K.H., Kim, C.H., Palukaitis, P., 1998. The coat protein of cucumber mosaic virus is a host range determinant for infection of maize. Mol. Plant Microbe Interact. 11, 351-357.

Salánki, K., Kiss, L., Gellért, Á., Balázs, E., 2011. Identification a coat protein region of cucumber mosaic virus (CMV) essential for long-distance movement in cucumber. Arch. Virol. 156, 2279-2283.

Schrödinger, L., 2016. Schrödinger Suite. Schrödinger, LLC, New York, NY.

Seo, E.-Y., Nam, J., Kim, H.-S., Park, Y.-H., Hong, S.M., Lakshman, D., Bae, H., Hammond, J., Lim, H.-S., 2014. Selective interaction between chloroplast $\beta$-ATPase and TGB1(L88) retards severe symptoms caused by alternanthera mosaic virus infection. Plant Pathol. J. 30, 58-67. http://dx.doi.org/10.5423/ppj.oa.09.2013.0097.

Shintaku, M.H., Zhang, L., Palukaitis, P., 1992. A single amino acid substitution in the coat protein of cucumber mosaic virus induces chlorosis in tobacco. Plant Cell 4, $751-757$.

Taliansky, M.E., García-Arenal, F., 1995. Role of cucumovirus capsid protein in longdistance movement within the infected plant. J. Virol. 69, 916-922.

Zhang, Y., 2008. I-TASSER server for protein 3D structure prediction. BMC Bioinform. $9,40$. 